\title{
Connecting the Dots: Integrating Cultural and Natural Resource Management in the United States
}

\author{
Michael Heilen, PhD, RPA (Statistical Research Inc.), USA \\ Jeffrey H. Altschul, PhD, RPA (SRI Foundation), USA
}

\begin{abstract}
Landholding agencies in the United States are under increasing pressure to integrate cultural and natural resource management approaches at a landscape level and to do so earlier and more comprehensively in planning processes. How to integrate management practices is poorly understood, however. An impediment to integration is that the laws, methods, and tools used in cultural and natural resource management differ significantly. Natural resource management protects or rehabilitates habitats and ecosystems that support endangered species, while cultural resource management focuses on identification and protection of individual sites. Agencies need to shift the focus from managing sites to defining cultural landscape elements and their relationship to natural resource management units and concerns. We suggest that agencies use archaeological predictive modeling, resource classes, and paleoenvironmental and cultural historical information to geospatially define cultural landscapes, predict resource distributions and values, and identify opportunities and protocols for collectively managing cultural and natural resources. As the United States faces increasing deregulation and limited preservation funding, we believe an integrated approach will be critical in preserving and protecting both cultural and natural heritage.
\end{abstract}

Keywords: Archaeological Modeling, Cultural Resource Management, Natural Resource Management, Landscape, Planning

\section{Introduction}

Many cultural and natural resources in the United States are managed by government agencies, such as the U.S. Bureau of Land Management (BLM), U.S. Department of Defense (DoD), U.S. Forest Service (USFS), and the U.S. National Park Service (NPS). Often, a single office within a land-managing agency oversees the management of both cultural and natural resources. Despite this, cultural and natural resources are managed separately, with little coordination, each following a separate set of laws, guidelines, and procedures. Land-managing agencies are beginning to recognize that this approach is costly and inefficient and that integration is necessary, but agencies are entrenched in existing practices and do not know where to begin. Integration requires agencies to adopt new practices that take advantage of emerging technologies and expanding information resources, as well as methodological and theoretical developments in environmental and social sciences. Perhaps most importantly, integration requires that: (1) natural resource management (NRM) approaches (Chiras and Reganold 2014; Chapin et al. 2009; Deal 2017) acknowledge the fundamental and integrative role that human activities have played within sustainable habitats and ecosystems; and (2) cultural resource management (CRM) (King 2011; McManamon 2018; Sebastian and Lipe 2010) abandon its 
reactive focus on individual projects and sites by adopting a proactive, relational, landscape approach.

Historic Landscape Characterization (HLC) has been used successfully in England and other countries to characterize all areas of a landscape according to their historic and ecological characteristics as currently manifested, in order to identify and manage landscape change (Barrett et al. 2007; Fairclough 2002, 2003; Fairclough et al. 1999). We suggest (in a similar manner to HLC) that landscape elements, such as areas where economic plants were procured and processed, can be geospatially defined and combined with archaeological locational, significance, and impact models to develop a cultural landscape model that predicts within a geospatial framework the structure and function of a cultural landscape as well as the significance and vulnerability of the resources contained within it. Cultural landscape models can then be intersected with NRM models and planning units to identify where CRM and NRM concerns converge and diverge and to identify potential management conflicts and synergies. This kind of modeling framework will allow agencies to open a constructive dialogue among stakeholders, planners, and land managers that considers cultural and natural resources together over broad areas and across multiple jurisdictions for long-term conservation and heritage preservation.

\section{The Management Problem}

Federal agencies in the United States are under increasing pressure to make their CRM and NRM programs more efficient and cost-effective. Although better integration of resource management early in the planning process has long been advocated, rarely has this objective been achieved. One impediment that is often cited for CRM's reluctance to integrate with NRM is the legal requirement by Federal agencies to consult with stakeholders, particularly Native Americans who have ties to the land that is being impacted, and regulatory agencies, such as the State Historic Preservation Office (SHPO). While the process of consulting on cultural resources can be time-consuming and difficult, it is not clear that integrating natural resources into the process would make it any more difficult. An integrated approach might actually be easier. Native Americans often conceptualize both cultural and natural resources holistically from a landscape perspective. Indeed, Native American perspectives are in greater alignment with an integrated landscape approach than they are with current resource management practice. Regulators are largely concerned about not making mistakes and ensuring that important sites are not missed or not adequately treated. This concern emphasizes individual project review, but comprehensive planning may actually alleviate regulator concerns by considering the entire resource base as a whole, instead of only those resources within the current project area.

So why has there been so little interest in integrated NRM and CRM plans? Part of the problem is that different sets of laws govern the protection and treatment of cultural and natural resources. Most CRM in the United States is compelled by the National Historic Preservation Act (NHPA) of 1966. Natural resources are considered under the National Environmental Policy Act (NEPA) of 1969 or the Endangered Species Act (ESA) of 1973. These laws are significantly different in terms of how they operate and have allowed agencies to manage and treat cultural and natural resources following disparate management practices and approaches.

Another fundamental difference between CRM and NRM programs rests in what is being 
managed. NRM efforts focus on conserving endangered species, not by managing the species or individuals themselves, but by managing key components of the habitats and ecosystems that sustain them. This conservation approach allows for broad issues that tie multiple resources together into a coherent ecological system to be addressed. CRM efforts, by contrast, focus on identification of important historic properties on a project-by-project basis, determining the ways in which individual resources are significant, and considering what to do about them if they will be impacted. Since the passage of the NHPA in 1966, CRM programs have conducted hundreds of thousands of projects and have recorded over a million archaeological sites, at a cost of tens of billions of dollars (Altschul 2016a; Altschul and Patterson 2010). Even though the law allows recording and managing large numbers of archaeological sites as parts of historic districts or as cases representing the same or similar cultural phenomena (i.e., in a multiple property documentation form), the reality is that individual archaeological sites are the subject of protection and management. The result of current approaches to CRM is a 'measles' map of thousands of isolated dots, with the management focus on avoiding each dot, if at all possible.

In today's CRM, there is little consideration of how sites are related to each other or to natural resources. Significant cultural resources that could be impacted by a project are either avoided or mitigated. It is not that the environmental and historical context of a site is irrelevant; indeed, context is everything in archaeological interpretation, including in CRM. But we do not manage the importance of a site or its historical or ecological context, we manage its physical properties. We might, for instance, consider a site used to process resources from a particular plant community well-managed if within the boundaries of the site the artifacts and features are avoided, even if all the surrounding plants, which were the focus of human behavior at the site, are destroyed. Or, we might consider a series of related sites individually as having little or no information potential and thus, to be of minimal management concern. When considered collectively as part of a coherent settlement pattern, transportation system, or resource processing and procurement system, by contrast, those same sites may be considered important in their ability to reveal information about an activity organization that would be largely invisible when investigated and interpreted at the level of individual sites. Asking whether an individual site can inform on a research question or satisfy a stakeholder concern is quite different from asking whether a collection of interrelated cultural and natural resources can address important research issues or stakeholder concerns. In short, current CRM practice conceptualizes and treats cultural resources as discrete, bounded entities whose physical contents can or cannot provide information about the past, largely in isolation of their social and ecological landscape context.

Developing integrated, long-term plans is difficult with such an approach. Creative mitigation approaches that set aside archaeological reserves, synthesize existing data, or disseminate important findings to the public are rarely undertaken (Altschul et al. 2018; Lipe 2010; Mayro and Doelle 2018). The consideration and treatment of historic properties in isolation, according to an ad hoc, reactive approach, does little to preserve the resource qualities and contexts that make cultural resources important. Tools, methods, and strategies are needed that can improve preservation outcomes by considering sites within a relational, landscape context.

We believe that CRM needs to transition from its traditional site- and project-based focus to a long-term, landscape-level focus that is integrated with NRM landscape approaches. 
This will allow CRM and NRM efforts to identify management conflicts and opportunities, adapt to changing conditions, and to consider resources from a broader, holistic, and more inclusive regional context. Mitigation measures should address entire classes of resources and pursue research and preservation problems relevant to multiple projects and stakeholder concerns. Instead of asking, what happened here? Or, how were these stone tools used? We need to ask, what did humans value in this region? How did they place themselves in relation to the area's natural resources and how did they interact with, manipulate, manage, and rely on those resources? How did interactions and relationships among people and resources change over time, and why? We need to identify effective means to study, interpret, and preserve cultural heritage at the scale of landscapes rather than at the scale of individual sites.

\section{Why Integrate Cultural and Natural Resource Management?}

There are several reasons why management of cultural and natural resources in the United States should be integrated. First, the divide between nature and culture is artificial. Cultural resources are treated independent of related natural resources. NRM approaches interpret human influence primarily as a disturbance regime that negatively alters and perturbs the structure and function of natural habitats and ecosystems, as if the healthiest habitats and ecosystems are those in which human influences are absent or have been removed. Yet, archaeologists and landscape ecologists increasingly understand this dichotomy to be false and empirically unjustifiable (Taylor and Lennon 2011; Wu 2010). Globally, virtually no landscape is independent of human influence. The impact of human activities on many aspects of the environment has been widespread over a long period (Amarosi et al. 1997; Butzer 1982; Denevan 1992; Grayson 2001; Kohler 1992; Redman 1999; Simpson et al. 2004; Stinchcomb et al. 2011; Van Andel et al. 1990).

Past societies can be viewed as so many completed experiments in human adaptation to particular natural and social environments. As modern society debates how to react to a changing global climate, mass migration, and growing economic inequality, it would do well to see what worked in the past and what did not. CRM can play an important role in providing a deep-time perspective on the roles that human activity played in the sustainability, resilience, or degradation of habitats and ecosystems. This unique perspective is otherwise inaccessible to environmental scientists who typically work with modern and recent historical data of no greater time-depth than the past few centuries (Barton et al. 2004; Butzer 1982; Crumley et al. 2017; Van der Leeuw and Redman 2002). Do we wish to conserve those habitats and ecosystems that we know about from modern observations and historical records or those that persisted with human involvement for centuries or millennia and that can only be reconstructed through archaeological and paleoenvironmental study?

Another reason to integrate CRM and NRM is that Native American stakeholders and other traditional communities consider cultural and natural resources together as a unified whole and are frustrated by the focus in CRM on individual sites (Barton et al. 2004; Hood 1996; Van der Leeuw and Redman 2002; Whittlesey 2004; Zedeño 1997, 2000). Necessarily, people place themselves within a landscape to make use of vital resources, such as potable water, specific plant and animal communities, mineral sources, productive soils, lakeshore and wetland habitats, and landscape features - such as mountain peaks, water sources, or earth fissures - that represent important social and economic values. Tribes are interested not 
only in archaeological sites but in the water sources, minerals, plant species, soils, habitats, and landmarks to which those sites are related. Collectively, all of these resources are seen as forming the basis of a Tribe's way of life and social identity, as well as that of their ancestors, to the extent that what might be considered a natural resource, such as a spring, could also be considered a cultural resource. People use environmental resources to sustain themselves, but they also alter and manage aspects of their environment (Harkin and Lewis 2007; Johnson et al. 2012).

Ultimately, landscape-level resource management requires a consideration of how resource patterns and relationships vary by management problem, scale, and units of analysis. The spatial, temporal, and social scale of a landscape depends on the scale of resource patterns, social activities, and ecosystem goods and services under consideration (Crumley and Marquardt 1990; Heilen 2005; Heilen et al. 2008; Wandsnider 1998). As Doelle et al. observe:

"...One might think of landscapes as encompassing the land and resources needed to support a particular community, ethnic group, population, or technological system. Ultimately, the scale and shape of a landscape is process- and problem-oriented. The size and configuration of a bunter-gatherer landscape for a pre-agricultural time period may be of a different size and shape than a later agricultural landscape. Thus, individual regional planning efforts in archaeology will likely have to consider multiple landscapes and may also need to consider, where possible, multiple spatial scales." (Doelle et al. 2016: 120).

We are not suggesting that landscapes need to be defined and managed as discrete, monolithic units much like how individual sites are defined and managed, only at a larger scale. What we are instead suggesting is that federal agencies manage cultural and natural resources together within a geospatial framework following a landscape perspective. The importance of such an approach is that it can support both project planning and long-term preservation by acknowledging the diverse values placed in cultural and natural resources as a means to identify management conflicts, challenges, and opportunities.

\section{The Artificial Separation of Nature and Culture}

Carl Sauer (1967a,b), a pioneer of landscape concepts in geography, made a classic distinction between cultural and natural landscapes. Sauer envisioned environments that had been minimally impacted by human activities as natural landscapes. Cultural landscapes were the material result of human interactions with natural landscapes. To Sauer, cultural landscapes represented the intersection of culture and the environment in a particular setting, including the built environment. At the same time, Sauer defined a landscape as the historically-contingent material result of the interaction of natural and cultural processes. The components of a landscape mutually define each other, giving rise to their collective organization and relatedness:

"The facts of geography are place facts; their association gives rise to the concept of landscape. Similarly, the facts of history are time facts; their association gives rise to the concept of period. By definition the landscape has identity that is based on recognizable constitution, limits, and generic relation to other landscapes, which constitute a general system. Its structure and function are determined by integrant, dependent forms. The landscape is considered, therefore, in a sense as having an organic quality." (Sauer 1967a: 321-322).

More recently, archaeologists have taken this interdependence a step further by envisioning 
landscapes as networks of people, places, and resources that enable and regulate the exchange of matter, energy, and information, much in the same way as do ecological networks. As such, a landscape can be conceptualized as an integrated socio-ecological system that sustains and reproduces both ecology and society (Heilen 2005; Heilen et al. 2008; Heilen and Reid 2009; Heilen and Vanderpot 2013; Schein 1997; Zedeño 1997, 2000; Zedeño et al. 1997). Landscape ecologists consider landscape as a mosaic of interacting spatial elements, such as patches or habitats that together form a pattern or process (Hargis et al. 1997; Kotliar and Wiens 1990; Pickett and Rogers 1997; Turner et al. 2001). Landscape elements include both natural features and habitats as well as anthropogenic features, such as roads, dams, settlements, fields, corrals, forts, and many other facilities.

The idea of 'wilderness' as an area untrampled by people remains a guiding principle of natural resource management. Yet, there is no such thing as a pristine wilderness. People are a part of their environment. For example, forests in the Border Lakes region of the United States and Canada that have been designated 'wilderness' would not exist without the intervention of fire management by First Nation Tribes (Larsen 2018). The false premise of the pristine wilderness leads to the erroneous conclusion that the ideal state of natural resources is one where human influence is absent. Yet, the reality is that many of the 'natural' systems we seek to conserve and restore are the result of past human tending and stewardship of those resources (Crumley 1994; Crumley et al. 2017). Removing the important role of human influence from the natural resource management equation ignores the long history of ecological entanglement between humans and their environment.

To understand and restore sustainable and resilient natural landscapes and ecosystems, NRM needs to understand the role that humans have played in their form, function, and stewardship. To do this, we suggest that an integrated approach may need to adopt a concept of anthropogenic services that would be analogous to the role of ecosystem services in ecology. By the same token, CRM needs to acknowledge the roles that natural resources have in structuring, sustaining, and reproducing culture and society and their relationship to the sites we seek to preserve.

\section{Current Status of Efforts to Integrate CRM and NRM}

Agencies and organizations in the United States are advocating that an integrated landscape approach be adopted. Such an approach has yet to be implemented in a compliance setting and methods for doing so are underdeveloped, however.

President Obama's Executive Order 13653 resulted in the development of a Priority Agenda for Enhancing the Climate Resilience of America's Natural Resources. The agenda defined a landscape as "a large area encompassing an interacting mosaic of ecosystems and human systems that is characterized by a set of intersecting management concerns. The landscape is not defined by the size of the area, but rather by the interacting elements that are meaningful to the management objectives" (Council on Climate Change Preparedness and Resilience Climate and Natural Resources Working Group 2014: 16). The National Park Service (NPS) defines a cultural landscape as "including both cultural and natural resources and the wildlife or domestic animals therein” (Birnbaum 1994: 1). In a similar vein, the European Landscape Convention (ELC), an international treaty adopted in 2000 by the Committee of Ministers of the Council of Europe and enacted in 2004, defines landscape as "an area, as perceived by people, whose character is the result of the action and interaction of natural and/or human factors" 
(Council of Europe 2000: 2). These definitions explicitly recognize the interrelatedness of cultural and natural resources in landscape-level management. How to use such a concept in resource management, however, is poorly defined.

Perhaps the most comprehensive attempt to integrate cultural and natural resource management in a landscape perspective was the federally-sponsored Landscape Conservation Cooperative (LCC). In 2009, the US Department of the Interior (DOI) established the LCC program "to provide a collaborative framework that could deliver the scientific information needed for effective management, and catalyze conservation planning and actions across multiple jurisdictions through partnerships" (National Academies of Sciences 2016: 1). The program vision is to foster effective management and conservation of "landscapes capable of sustaining natural and cultural resources for current and future generations" (National Academies of Sciences 2016: 8). A major program goal is to ensure "natural and cultural resources are conserved at large landscape and seascape scales, guided by the collaborative application of science, experience, and cultural or traditional ecological knowledge and the generation of new conservation knowledge" (National Academies of Sciences 2016: 27). Objectives for achieving this purpose include the following:

- Objective 3-1: identify and develop spatial, biological, and cultural data evaluation tools across the network; and support assessment tools for climate change and climate adaptation planning for important cultural and subsistence resources.

- Objective 3-2: include resource managers, cultural practitioners and Indigenous peoples in framing resource-conservation issues and management objectives.

- Objective 3-3: place focus on cooperating, sharing, cooperative synthesis of data, and communication.

A failure of the program is an over-emphasis on natural resource concerns and the glaring absence of approaches that consider cultural resources. The National Academies of Sciences judged the LCC approach as underemphasizing cultural resources and lacking discernible methods for integrating cultural resources in landscape-level management initiatives. The lack of emphasis on cultural resource management in the development of the program is "why the methods by which the LCCs will be addressing cultural resources are still not clear." (National Academies of Sciences 2016: 21, emphasis added).

The DOI's struggles with cultural resources are also felt by DOI's land managing agencies (Clement et al. 2014). For example, both the BLM and the NPS are currently shifting their focus from site-based planning to landscape-scale, regional planning efforts and are actively seeking approaches and input for doing so. These federal land managing agencies are investigating alternative approaches that shift from a project-by-project methodology to a more programmatic and holistic approach that considers the nature and distribution of cultural resources under NHPA and NEPA.

The BLM has recently developed a Landscape Approach to the Management of Public Lands that consists of five components: rapid ecoregional assessment (REAs), ecoregional direction, field implementation, monitoring and adaptive management, and science integration. REAs are essentially geospatial models of species distributions, ecosystems, environmental hazards, habitats, and ecosystems that are used to guide the approach and are analogous to 
archaeological models that we discuss later in this paper. Although designed primarily with ecological management issues in mind, the basic intent and method of the BLM's approach should apply equally well to CRM issues and could be adapted to synergistically address both ecological and CRM issues. However, like the LCC, efforts to include cultural resources in the BLM's landscape approach are far behind those of natural resources and clear methods for doing so are not established (Heilen et al. 2015).

NPS is scaling up planning and management efforts to focus on maintaining connectivity among cultural resources and natural habitats and to devise standards and guidelines for recognizing cultural landscapes as a historic property type. NPS has recently developed a climate change strategy aimed at managing impacts to cultural resources from a landscape perspective (Rockman et al. 2016).

The integrated management of natural and cultural resources from a landscape perspective is not only a growing concern among federal agencies in the United States, it is also a major issue internationally. For example, in 2013 IUCN and ICOMOS launched The World Heritage Convention the Connecting Practice Project. Recognizing disconnectedness and fragmentation in resource management processes, the project was established to promote integrated landscape approaches to cultural and natural resource management. The primary goal of the project is the following:

"To explore, learn and create new methods that are centered on recognizing and supporting the interconnected biocultural character of the natural, cultural and social values of highly significant landscapes and seascapes" (ICOMOS \& IUCN 2015: 2).

Many countries and international organizations are moving toward managing cultural heritage from a landscape perspective and are struggling with some of the same issues faced in the United States. UNESCO, for example, has developed a guidebook for management: World Heritage Cultural Landscapes (Mitchell et al. 2009). In Europe, the HERCULES project has issued policy recommendations for implementing the ELC through an integrated landscape approach to environmental governance and sustainable landscape conservation (Mann et al. 2016). Existing approaches are designed to address the particular laws, management concerns, and historical development of their host countries and, as such, do not necessarily match compliance requirements and resource management needs of CRM and NRM programs in the United States. In short, while many agencies recognize the need, no federal agency in the United States has integrated CRM and NRM; tools and methods for doing so are underdeveloped and unclear; and landscape-level management approaches are dominated by natural resource concerns that ignore or undervalue the role of culture.

\section{Applying a Landscape Perspective in CRM}

By applying a landscape perspective, a resource can consist of a constellation of sites and isolates such as those that collectively represent a resource procurement and processing system, a transportation network, or a military theater. One reason for adopting a landscape approach is that it does not focus eligibility requirements or data recovery schemes exclusively on sites, but balances and weighs the significance of individual resources with reference to the entire range of material on the landscape as the study universe (Altschul 2014; Heilen and Vanderpot 2013). This way, CRM programs can consider multiple properties together as a class to make creative, programmatic decisions about where and how to place efforts, rather 
than spread scarce preservation dollars thinly and reactively, in the same ways, wherever and whenever an undertaking comes up or an agency's mission changes.

To use a landscape perspective, agencies need to know how sites are related to each other, the built environment, and to natural resources to form a land use system, economic activity, or way of life. The agency must determine which cultural resources are truly important and what is important about these resources. Is it the resource itself or the resources and land use system to which the resource (or resource class) relates? Are all resources of a given type or class of equal importance or value? Do they all need to be treated the same way? Can representative samples and the best examples of important resources be studied and preserved to make the most practical and efficient use of scarce preservation dollars?

Government agencies must abandon a reactive, as-needed approach to CRM and instead consider resources at a landscape scale. This will allow agencies to a) flexibly manage their assets; b) identify management conflicts and opportunities early on in planning processes; c) address the concerns of tribal and other stakeholders by considering resource relationships and interdependencies; and d) incorporate the built environment into its natural and cultural landscape setting. The way we think CRM and NRM can be brought into greater alignment with each other is through geospatial modeling.

\section{The Role of Geospatial Modeling in Landscape-Level Planning and Management}

To do so, we begin with our definition of landscape: a naturally bounded region shaped by human interaction into a dynamic mosaic of interacting landscape elements and habitats. Landscapes are not static environments to be managed as never-changing sets of plants and animals but are shaped by changes in environments, climate, and socio-ecological interactions. Our goal is to define the parameters of the complex relationships between natural and cultural elements in a region and then create GIS-based tools that provide transparent and objective guidelines on how best to manage the current set of natural and cultural resources in a particular setting. Historic contexts may discuss landscape parameters relevant to interpreting and managing cultural resources, but unless these are geospatially defined, associated with particular management concerns, and made available within an environmental resource management GIS, there is no clear way to consider these cultural factors alongside natural resource concerns in programmatic compliance and spatial planning. And, there is no unified method for identifying the sensitivity of cultural and natural resources to Native American stakeholders who routinely insist that cultural and natural resources be viewed as a unified whole. When it comes to seeing where cultural and natural resource management concerns converge and can be brought into alignment to streamline management, we are essentially dealing with a black box.

Archaeological predictive modeling has been identified as one means of streamlining inventory, evaluation, and project design that could result in considerable cost and time savings for conducting CRM (Green et al. 2012; Judge and Sebastian 1988). Modeling supports the preservation of cultural resources by identifying potential locations of valued resources early in the planning process and by allowing managers to make proactive decisions regarding inventory, evaluation, and treatment options. For example, models of archaeological sensitivity can be used as planning tools to guide survey efforts by helping managers and planners decide on the level of effort, scheduling, and potential costs of CRM in different areas of installation. Additional kinds of archaeological models can be used to predict site 
significance or impact risks resulting from unanticipated discovery, encroachment, or climate change (Altschul 1988; Heilen et al. 2012, 2013, 2016; Heilen and Altschul 2016; Heilen et al. 2018; Sebastian 2010; Rockman et al. 2016).

Modeling has been a useful tool in compliance and planning in NEPA and NHPA. Models establish a broad, inclusive understanding of where sites are known or expected to occur and which ones are likely to be considered significant or to be impacted. What predictive models have done well is identify sensitivities and risks. What they do not often do well within a landscape context is explain the behavioral and cultural relevance of historic properties, particularly historical-period archaeological resources and the historic built environment. Incorporating Indigenous views in predictive models is less a technological problem (e.g. by converting oral information into GIS layers) as much as it is a sociological problem (i.e., building sufficient trust for Indigenous groups to provide this information). It should not be lost, however, that predictive models have been used by managers to open dialogue with Indigenous peoples about why sites are located where they are from their perspective, what sites mean to them, and why particular sites and natural resources are (or are not) important.

The scientific adequacy and managerial utility of modeling archaeological site locations has been illustrated by a series of projects sponsored by the Legacy Resource Management Program (Legacy) and the Environmental Security Technology Certification Program (ESTCP). These projects have shown that archaeological models work well in predicting site location and significance on agency-managed lands; can be successfully refined and validated; and can be integrated into programmatic approaches (Altschul et al. 2004; Cushman and Sebastian 2008; Green et al. 2012; Heilen et al. 2012; Sebastian et al. 2005). Archaeological models can be used to fulfill inventory requirements, anticipate effects, and make proactive, streamlined management decisions regarding where to place CRM efforts. Numerous investigations have explored methods for improving the strength and utility of models by applying a broad array of inductive and deductive techniques to model site location in diverse contexts and have continued to improve (Aldenderfer and Maschner 1996; Chen et al. 2013; Comer and Harrower 2013; Kvamme 1989, 1990, 1999; Lock and Stančič 1995; Mehrer and Wescott 2006; Wescott and Brandon 2000; Young 2008; Zeanah et al. 1995; Zeidler 2001).

In response to the growing need to incorporate landscape-level approaches in CRM, the Society for American Archaeology convened in 2014 a Task Force to assess current approaches to regional planning (Altschul 2016b; Doelle et al. 2016). The Task Force recommended that approaches be taken in CRM to move from a reactive site-based, projectby-project approach to a proactive, regional, landscape-level approach to management. What they advocate is that we need to embrace landscape-level archaeological modeling to make better use of decades of accumulated CRM data and to develop transparent protocols for tackling the broad management issues we face today.

Modeling has advanced significantly over the past several decades. There are multiple kinds of models that can be developed to predict where sites are located, how resources will be valued; impacts to sites by change agents such as development, wildfires, erosion, and climate change; and how sites relate to other resources and to their environment. We refer to these as locational models, significance models, impact models, and cultural landscape models. 


\section{Locational Models}

Archaeologists have been building locational models for a long time (Judge and Sebastian 1988). Locational models predict where particular types of sites are likely to be located. A major advantage of such models is that they allow us to consider planning areas that have not been surveyed or have only been sample surveyed. Most federal land has yet to be surveyed and is usually only surveyed after a project has been planned. Locational models help managers identify sensitive areas before the footprint of a project is decided and to anticipate the kinds and densities of cultural resources likely to be impacted by project alternatives. This kind of information can aid in the identification of areas where especially important site types (such as residential sites or sacred sites) are likely to be located; the identification of areas where common and redundant sites are likely to be found; the interpretation of land use according to site function and temporal or cultural affiliation; and the identification of cases where a site appears in an anomalous location, possibly requiring further investigation. Similar models are also routinely developed for natural resource management. For example, a REA for the state of New Mexico was developed that identifies watersheds at risk based on fire threat, risk to water supplies, forest health decline, risk to fish and wildlife habitat, and economic opportunities. An archaeological sensitivity model was also recently created by the BLM for southern New Mexico and covers many of the same areas as the BLMs REA (Fig. 1) (Heilen et al. 2013). There is no reason why these two maps cannot be used together in long-term planning.

\section{Significance Models}

Formal evaluation used to identify site significance in the United States is slow and expensive. As a result, the vast majority of resources have not been formally evaluated. But we still need to know the ways in which the thousands of resources that have been identified are likely to be important and how they would need to be preserved and treated. Models can now be developed to predict resource significance and the ways in which resources can contribute to preservation and research goals (Heilen and Altschul 2016; Heilen et al. 2012, 2016; McManamon et al. 2016; Sebastian 2010). These models use existing data and information on the ways in which resources with particular attributes have been valued in order to predict significance. Rather than identify in a binary, case-by-case fashion whether a site is likely to be eligible or not eligible for listing on the National Register of Historic Places (NRHP) - a key benchmark used in the United States for identifying whether a site needs to be considered in project planning - significance models can predict the relative importance of a site along a sliding scale and the kinds of resource values to which a site is likely to pertain. For example, the U.S. Navy funded development of a significance model for San Clemente Island in California that successfully differentiates thousands of similar shell midden sites according to their research potential (Fig. 2) (Heilen et al. 2016). In developing a significance model, stakeholder input is needed to identify variables that are important to deciding on significance and the ways in which different resource types and characteristics are valued. Heilen and Altschul (2016; see also Heilen et al. 2018) have also devised an experimental measure, referred to as the eligibility index, that they used to assess the relative importance of resource types and characteristics based on prior evaluations of the eligibility of sites for listing on the NRHP. 

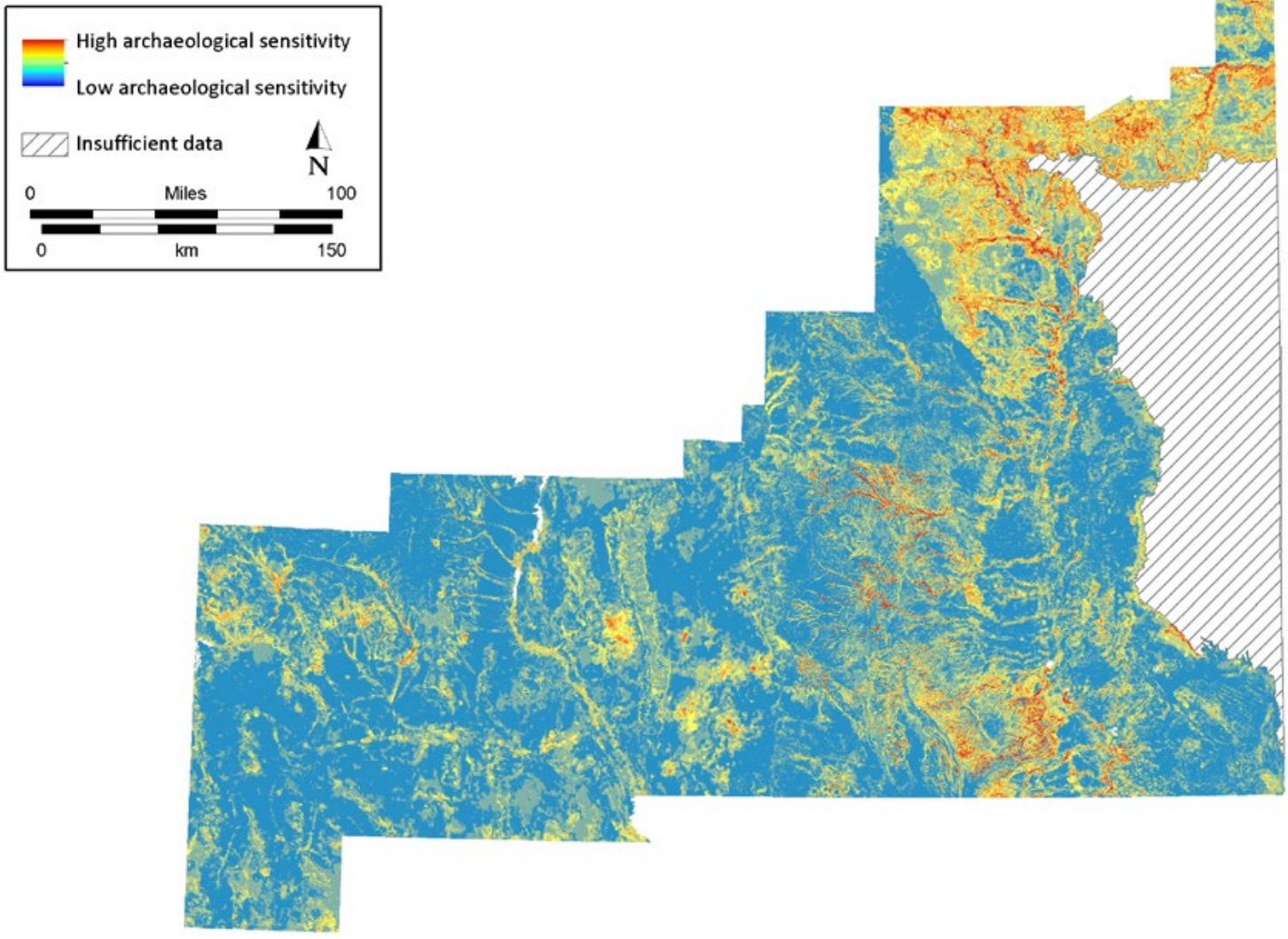

Figure 1. Example of a model of archaeological site location created for the U.S. Bureau of Land Management in southern New Mexico, United States.

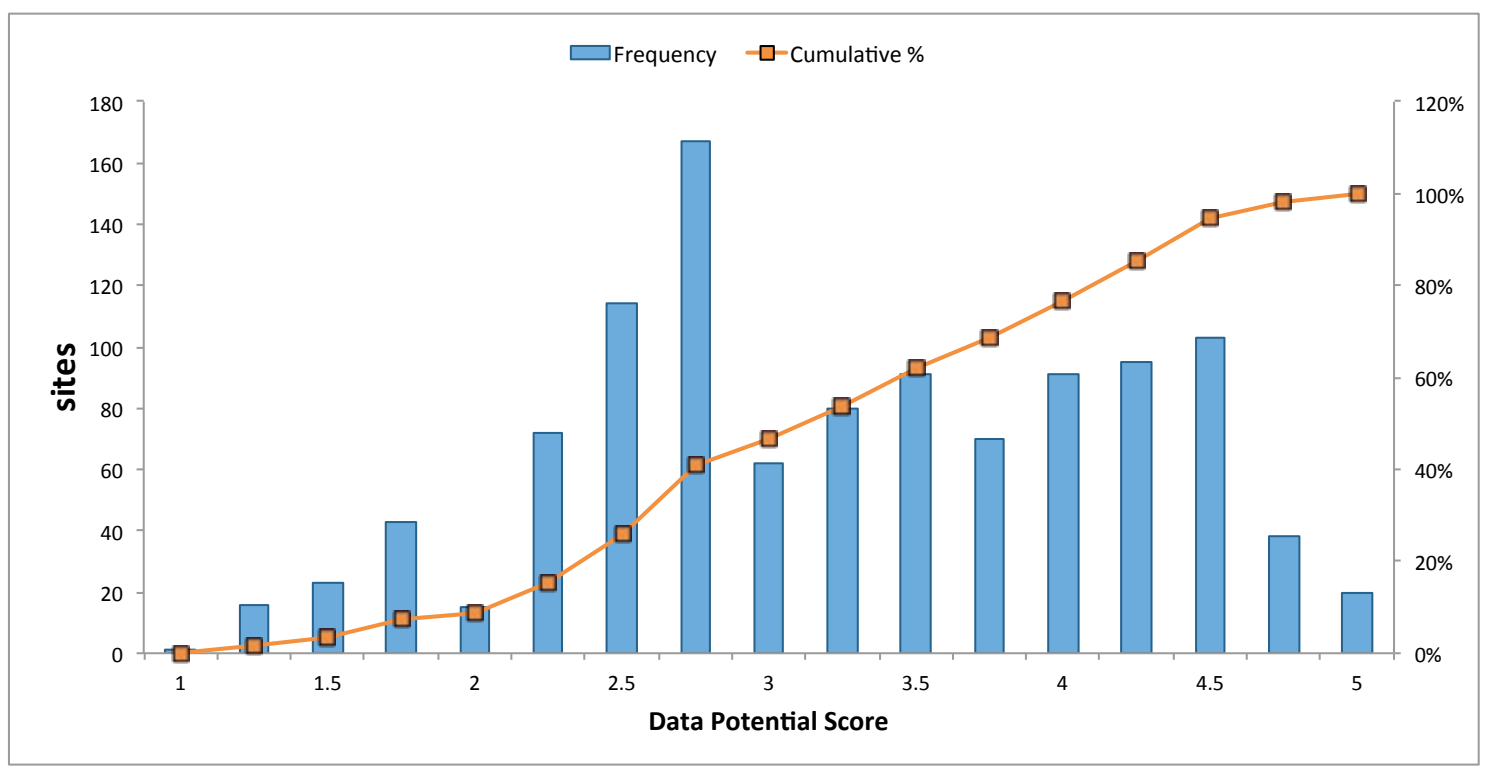

Figure 2. Frequency diagram of overall data potential scores calculated for shell midden sites on San Clemente Island, California, United States $(1=$ lowest data potential; $5=$ highest data potential). 


\section{Impact Models}

Models predicting impacts to cultural resources can be developed based on historical satellite imagery and models predicting the risk of flooding, wildfire, erosion and other change agents. We like to call these impact models and may also be referred to as vulnerability models. For example, the U.S. National Oceanic and Atmospheric Administration (NOAA) created a series of models of coastal inundation expected to result from sea level rise. These models were used by Heilen and Altschul (2016; see also Heilen et al. 2018) to predict impacts to archaeological sites on the Atlantic coast of the United States so that decisions can be made about which sites to study and preserve before they are lost (Fig. 3). A similar approach was used by Anderson et al. (2017) to assess the impact of sea level rise on coastal sites along the eastern seaboard of the United States.

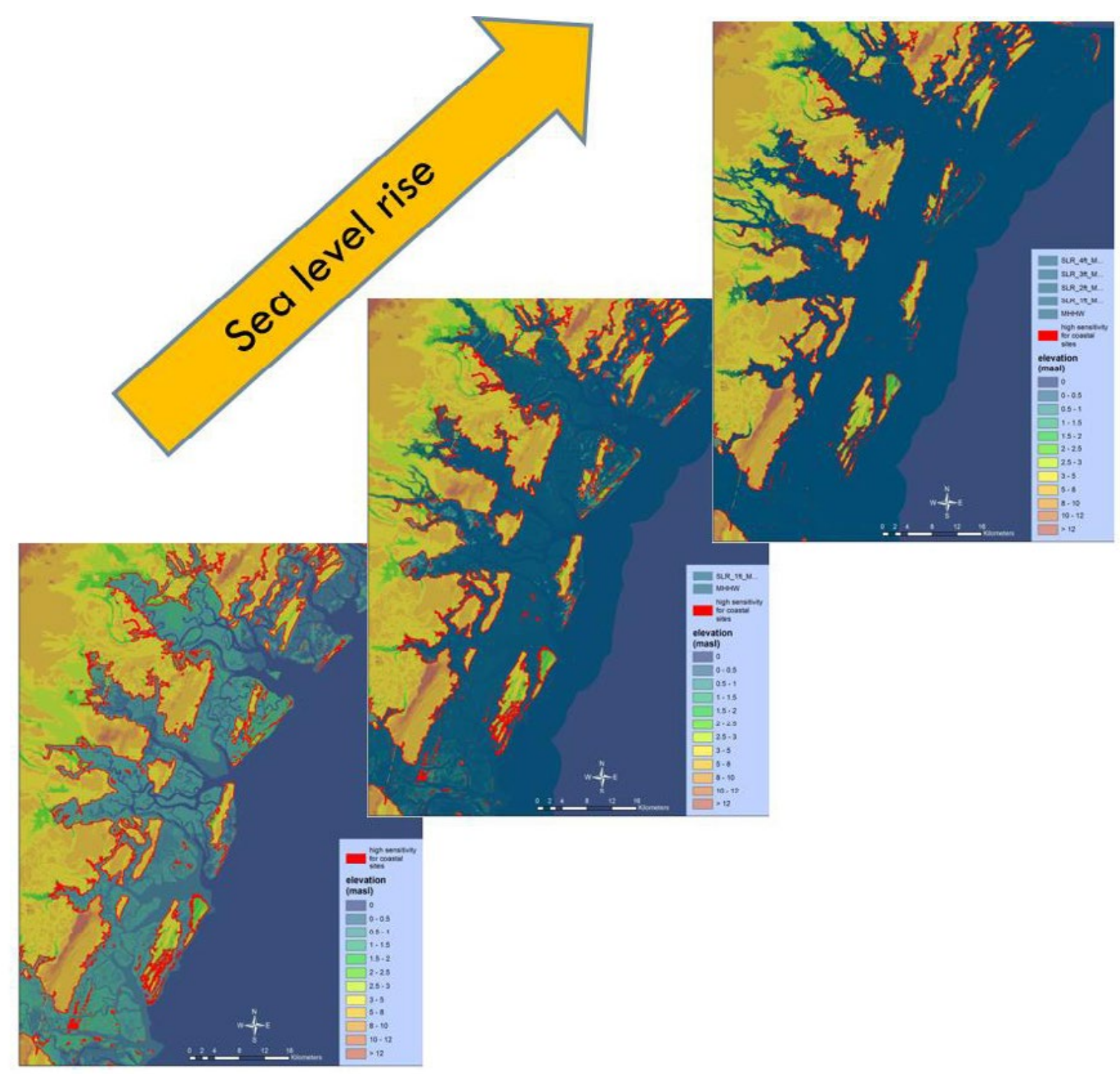

Figure 3. An example of an impact model predicting the effect of coastal flooding and sea level rise on archaeological sites on the Atlantic coast of Georgia, United States. 


\section{Cultural Landscape Modeling}

Another kind of modeling that could help us to manage resources at a landscape level and connect them to natural resources is cultural landscape modeling. To our knowledge, such models have yet to be developed in the United States, but analogous models have been used in both developing (see Mitchell et al. 2009) and industrial countries. For example, one approach developed by Historic England (the national heritage body for England) to characterize the landscape as it exists today is Historic Landscape Characterization (HLC) (Fairclough 2002, 2003; Fairclough et al. 1999). HLC involves segmentation and interpretation of the entire landscape through the use of aerial photographs, historic maps, and geospatial tools to define landscape elements according to "variations in historic development-the resulting HLC maps look rather like ecologists' habitat maps or soil scientists' soil maps" (Turner 2006: 385). The approach is used to guide both heritage management and research in England and, as an experiment, has been successfully applied in the United States at Fort Hood, Texas where the environmental and cultural context is very different than in England (Barrett et al. 2007). Similar approaches have been adopted by other European countries with the establishment of the ELC.

To create a geospatial cultural landscape model, landscape elements that form a cultural landscape can be mapped to include natural features, habitats, and anthropogenic features, such as roads, dams, settlements, fields, corrals, forts, and many other facilities. Mapping out the landscape in this way will help to identify convergence between natural resource planning units and culturally sensitive areas and to understand how different components of the resource landscape are related.

Figure 4 shows a kernel density plot of the distribution of thermal features on the Barry M. Goldwater Range in the desert southwest of the United States (Heilen and Altschul 2014). Vanderpot et al. (2008) argue that the thermal features were used to process native plants, particularly succulents, grasses and other seed-bearing plants, and legumes. The thermal features are distributed linearly along ephemeral drainages, where Indigenous people would have had access to wood for fires and water for camping. The targeted plants would have been found in other parts of the alluvial valleys and slopes of the adjoining mountain ranges; areas identified by the distribution of isolated flaked stones used as expedient tools to collect edible plant parts, such as buds, fruits, and seeds Many of these same plants are mainstays in the diet of the endangered Sonoran pronghorn. The kernel density map, therefore, helps identify areas where annual plants used by prehistoric foragers once thrived, which are now important habitats for the Sonoran pronghorn, an endangered species protected by federal law.

\section{Conclusions}

Cultural and natural resource management in the United States is not integrated but can be integrated through landscape-level planning. To do this, CRM needs to shift from a reactive, site- and project-based approach, to a proactive, landscape approach. This is the same direction that NRM is heading in the United States, but NRM is further along, and in defining landscape approaches have paid little to no attention to the preservation of cultural resource values. The most straightforward route to establishing common ground between CRM and NRM is through archaeological modeling, particularly through the construction of locational, significance, impact, and cultural landscape models in a GIS and their integration with NRM models within a geospatial framework. 


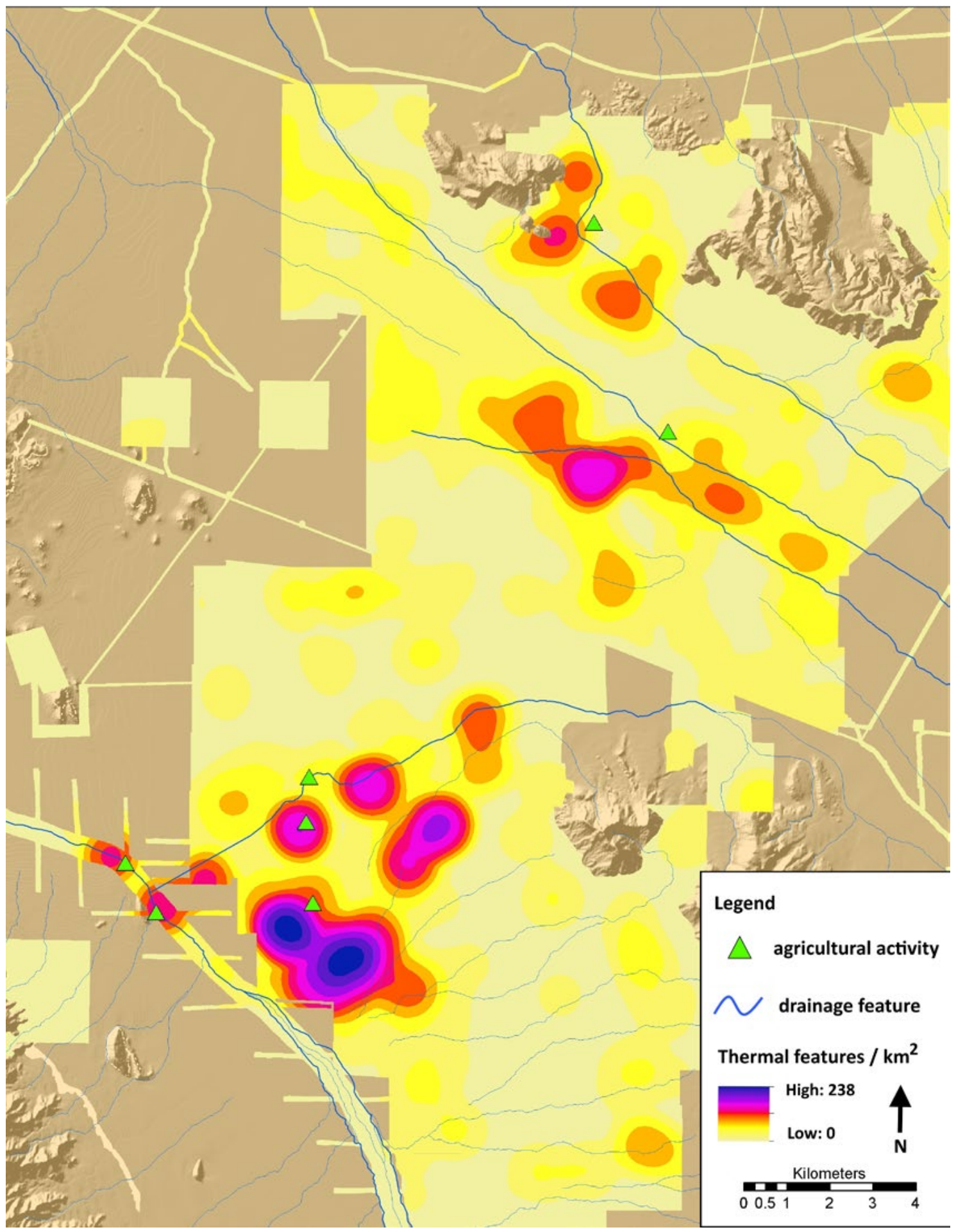

Figure 4: Kernel density plot depicting areas used by prehistoric foragers to process plants in thermal features, in the Western Papaguería region of the southwestern United States.

Large areas that are sensitive to both natural and cultural resources is a serious management concern. The opposite is also true. Modeling provides a transparent, systematic process for leveraging data to predict trends and outcomes. Modeling products and protocols for their implementation can be readily integrated into spatial planning platforms accessible to land planners. This will allow for shared stewardship opportunities and resource management 
conflicts to be identified early, address stakeholder concerns, and provide for a more streamlined, efficient, and productive approach to resource management.

\section{References}

Aldenderfer, M., \& Maschner, H. (eds), 1996. Anthropology, Space and Geographic Information Systems. New York (NY): Oxford University Press.

Altschul, J., 1988. Models and the modeling process, in: W. Judge \& L. Sebastian (eds) Quantifying the Past and Predicting the Past: Theory, Method, and Application of Archaeological Predictive Modeling. Denver (CO): US Bureau of Land Management, 61-96.

Altschul, J., 2014. Landscapes: a tool for cultural resource management?, in: SAA Government Affairs and International Government Affairs Update, May 2014, 6-7. Electronic document, http://ecommerce.saa.org/saa/staticcontent/staticpages/GovAff/May2014.pdf, accessed 3 August 2016).

Altschul, J., 2016a. The role of synthesis in American archaeology and cultural resource management as seen through an Arizona lens. Journal of Arizona Archaeology 4(1), 68-81.

Altschul, J., 2016b. The Society for American Archaeology's task forces on landscape policy issues. Advances in Archaeological Practice 4(2), 102-105.

Altschul, J., Kintigh, K., Klein, T., Doelle, W., Hays-Gilpin, K., Herr, S., Kohler, T., Mills, B., Montgomery, L., Nelson, M., Ortman, S., Parker, J., Peeples, M. \& Sabloff, J., 2018. Fostering collaborative synthetic research in archaeology. Advances in Archaeological Practice 6(1), 19-29.

Altschul, J., \& Patterson, T., 2010. Trends in employment and training in American archaeology, in: W. Ashmore, D. Lippert, \& B. Mills (eds), Voices in American Archaeology. Washington (DC): SAA Press, 291-316.

Altschul, J., Sebastian, L. \& Heidelberg, K., 2004. Predictive Modeling in the Military: Similar Goals, Divergent Paths. Legacy Resource Management Program Project No. 03-167. Preservation Research Series 1. Rio Rancho (NM): SRI Foundation.

Amarosi, T., Buckland, P., Dugmore, A., Ingimundarson, J. \& McGovern, T., 1997. Raiding the landscape: human impact in the Scandinavian north Atlantic. Human Ecology 25(3), 491-518. Anderson, D., Bissett, T., Yerka, S., Wells, J., Kansa, E., Kansa, S., Myers, K., DeMuth, R. \& White, D., 2017. Sea-level rise and archaeological site destruction: An example from the southeastern United States using DINAA. PLOS One 12(11): e0188142.https://doi. org/10.1371/journal.pone.0188142.

Barrett, G., Dingwall, L., Gaffney, V., Fitch, S., Huckerby, C. \& Maguire, T., 2007. Heritage Management at Fort Hood, Texas: Experiments in Historic Landscape Characterization, in: L. Dingwall \& V. GafFney (eds). Oxford, England: Archaeopress.

Barton, C., Bernabeu, J., Aura, J., Garcia, O., Schmich S. \& Molina, L., 2004. Long-term socioecology and contingent landscapes. Journal of Archaeological Method and Theory 11(3), 253-295. Butzer, K., 1982. Archaeology as Human Ecology: Method and Theory for a Contextual Approach. Cambridge: Cambridge University Press.

Chapin III, F., Kofinas, G. \& Folke, C. (eds), 2009. Principles of Ecosystem Stewardship: Resilience-Based Natural Resource Management in a Changing World. New York: Springer.

Chen, L., Comer, D., Priebe, C., Sussman, D. \& Tilton, J., 2013. Refinement of a method of identifying probably archaeological sites from remotely sensed data, in: D. Comer \& M. Harrower (eds), Mapping Archaeological Landscapes from Space. New York (NY): Springer, 251-258. 
Chiras, D., \& Reganold, ,2014. Natural Resource Conservation: Management for a Sustainable Future, $10^{\text {th }}$ edition. Harlow: Pearson Education Limited.

Clement, J., Belin, A., Bean, M., Boling, T. \& Lyons, J., 2014. A Strategy for Improving Mitigation Policies and Practices of the Department of the Interior: A Report to the Secretary of the Interior from the Energy and Climate Change Task Force. Washington, D.C. Electronic document, http: / / www.doi.gov/news / upload / Mitigation-Report-to-the-Secretary_ FINAL_04_08_14.pdf, accessed August 3, 2016.

Comer, D., \& Harrower, M. (eds), 2013. Mapping Archaeological Landscapes from Space. Springer Briefs in Archaeology. New York (NY): Springer.

Council on Climate Change Preparedness and Resilience Climate and Natural Resources Working Group, 2014. Enhancing the Climate Resilience of America's Natural Resources. Washington, DC: The Departments of Defense, Interior, and Agriculture, the Environmental Protection Agency, the National Oceanic and Atmospheric Administration, the Federal Emergency Management Agency, and the U.S. Army Corps of Engineers.

Council of Europe, 2000. European Landscape Convention, European Treaty Series No. 176, Florence, accessed 9 Dec 2019, https://rm.coe.int/1680080621.

Crumley, C. (ed.), 1994. Historical Ecology: Cultural Knowledge and Changing Landscapes. Santa Fe (NM): SAR Press.

Crumley, C., Kolen, J., de Kleijn, M. \& van Manen, N., 2017. Studying long-term changes in cultural landscapes: outlines of a research framework and protocol. Landscape Research 42:(8), 880-890.

Crumley, C., \& Marquardt, , 1990. Landscape: A Unifying Concept in Regional Analysis, in: K. Allen, S. Green \& E. Zubrow (eds) Interpreting Space: GIS and Archaeology. London: Taylor and Francis, 73-79.

Cushman, D., \& Sebastian, L., 2008. Integrating Archaeological Models: Management and Compliance on Military Installations. Preservation Research Series 7. Rio Rancho (NM): SRI Foundation.

DeAL, K., 2017. Wildlife and Natural Resource Management, $4^{\text {th }}$ edition. United States: Cengage Learning.

Denevan, W., 1992. The pristine myth: The landscape of the Americas in 1492. Annals of the Association of American Geographers 82(3), 369-385.

Doelle, W., Barker, P., Cushman, D., Heilen, M., Herhahn, C. \& Rieth, C. 2016. Incorporating archaeological resources in landscape-level planning and management. Advances in Archaeological Practice 4(2), 118-131.

FairCLOUgh, G., 2002. Steps towards the integrated management of a changing landscape: Historic Landscape Characterisation in England, in: G. SwENSEN (ed.), Cultural Heritage on the Urban Fringe. Oslo: Norsk Institut for Kulturminneforskning, 29-39.

FAirclough, G., 2003. 'The long chain': archaeology, historical landscape characterization and time depth in the landscape, in: H. PALANG, \& G. Fry (eds), Landscape Interfaces: Cultural Heritage in Changing Landscapes. Dordrecht: Kluwer, 295-318.

Fairclough, G., Lambrick, G. \& McNab, A., 1999. Yesterday's World, Tomorrow's Landscape: The English Heritage Historic Landscape Project 1992-94. London: English Heritage.

Grayson, D., 2001. The archaeological record of human impacts on animal populations. Journal of World Prehistory 15, 1-68.

Green, P., Altschul, J., Heilen, M., Cushman, D., Homburg, J., Trampier, J., Hayden, W. \& Lerch, M., 2012. Integrating Archaeological Modeling in DoD Cultural Resource Compliance. Final Report submitted to the Environmental Security Testing Certification Program, U.S. Department of Defense. Rio Rancho (NM): SRI Foundation. 
Hargis, C., Bissonette J. \& David, J., 1997. Understanding measures of landscape pattern, in: J. Bissonette (ed.), Wildlife and Landscape Ecology: Effects of Pattern and Scale. New York (NY): Springer-Verlag, 231-261.

Harkin, M. \& Lewis D. (eds), 2007. Native Americans and the Environment: Perspectives on the Ecological Indian. Lincoln (NE): University of Nebraska Press.

Heilen, M., 2005. An Archaeological Theory of Landscapes. Ph.D. dissertation, University of Arizona. Ann Arbor (MI): University Microfilms.

Heilen, M., \& Altschul, J., 2014. Modeling sustainability and resilience through the investigation of critical habitats: a view from the US southwest. Paper presented at the $20^{\text {th }}$ Annual Meeting of the European Association of Archaeologists, Istanbul, Turkey.

Heilen, M., \& Altschul, J., 2016. Cultural Resources Phase I Efforts for Modeling Site Location in Georgia. Report submitted to the Georgia Department of Natural Resources Historic Preservation Division. Tucson (AZ): Statistical Research.

Heilen, M., Altschul, J. \& Lüth, F., 2018. Modelling Resource Values and Climate Change Impacts to Set Preservation and Research Priorities. Conservation and Management of Archaeological Sites 20(4), 261-284.

Heilen, M., Altschul, J., Reddy, S., Heckman, R. \& Norris, S., 2016. Locational and Significance Modeling at San Clemente Island, California. Technical Report 15-58. Redlands (CA): Statistical Research.

Heilen, M., Leckman, P., Byrd, A., Homburg, J. \& Heckman, R., 2013. Archaeological Sensitivity Modeling in Southern New Mexico: Automated Tools and Models for Planning and Management. Technical Report 11-26. Tucson (AZ): Statistical Research.

Heilen, M. \& ReID, J., 2009. A landscape of gamble and guts: commodification of land on the Arizona frontier, in: B. Bowser \& M. Zedeño (eds), The Archaeology of Meaningful Places. Salt Lake City (UT): University of Utah Press, 132-148.

Heilen, M., Reid, J. \& Schiffer, M., 2008. Landscape formation processes, in: B. David \& J. Thomas (eds), Handbook of Landscape Archaeology. Walnut Creek (CA): Left Coast Press, 601-608.

Heilen, M., Sebastian, L., Altschul, J., Leckman, P. \& Byrd, A., 2012. Modeling of Archaeological Site Location and Significance at White Sands Missile Range, New Mexico. Technical Report 12-06. Tucson (AZ): Statistical Research.

Heilen, M., \& Vanderpot, R., 2013. Pathways to Preservation: A Research Design and Heritage Management Plan for the Barry M. Goldwater Range East. Technical Report 13-05. Tucson (AZ): Statistical Research.

Hood, J. E., 1996. Social relations and the cultural landscape, in: R. YAmin \& K. Bescherer Metheny (eds) Landscape Archaeology: Reading and Interpreting the American Historical

Landscape. Knoxville: University of Tennessee Press, 121-146.

ICOMOS \& IUCN, 2015. Connecting Practice Project: Final Report. Accessed 9 Dec 2019, http://www.iucn.org/sites/dev/files/content/documents/connecting_practice_report_ iucn_icomos.pdf.

Johnson, S., Abrams, M. \& Rush, L., 2012. Using Black Earth and Remote Sensing Of Indicator Plants for Identification of Prehistoric Archaeological Sensitivity and Potential Site Integrity in the Eastern Woodlands: Recommendations for Applying Results to DoD Modeling Initiatives. Final report, US Department of Defense Legacy Resource Management Program Project 10-416.

Judge, W. \& Sebastian L. (eds), 1988. Quantifying the Past and Predicting the Past: Theory, Method, and Application of Archaeological Predictive Modeling. Denver (CO): USDI Bureau of Land Management, 61-96. 
KING, T. (ed.), 2011. A Companion to Cultural Resource Management. Chichester, West Sussex, UK: Wiley-Blackwell.

KoHLer, T., 1992. Prehistoric human impact on the environment in the upland North American southwest. Population and Environment 13(4), 255-267.

KotLiar, N. \& Wiens, J. 1990. Multiple scales of patchiness and patch structure: a hierarchical framework for the study of heterogeneity. Oikos 59, 253-260.

Kvamme, K., 1989. Geographic information systems in regional archaeological research and data management, in: M. SCHIFFER (ed.), Archaeological Method and Theory, Volume 1. Tucson (AZ): University of Arizona Press, 139-203. Kvamme, K., 1990. The fundamental principles and practice of predictive archaeological modeling, in: A. Voorrips (ed.), Mathematics and Information Science in Archaeology: A Flexible Framework. Bonn, Germany: HOLOS-Verlag, 275-295.

Kvamme, K., 1999. Recent directions and developments in geographical information systems. Journal of Archaeological Research 7(2), 153-201.

Larsen, E., 2018. People, Fire, and Pines in the Border Lakes Region of North America. The Synthetic Report: Newsletter of the Coalition for Archaeological Synthesis 1(1), 3-4.

LiPE, W., 2009. Archaeological values and resource management, in: L. SEBASTIAN \& W. LIPE (eds), Archaeological \& Cultural Resource Management: Visions for the Future. Santa Fe (NM): School for Advanced Research Press, 41-63.

Lock, G. \& StanČIČ, Z. (eds), 1995. Archaeology and Geographic Information Systems: A European Perspective. London: Taylor and Francis.

McManamon, F. (ed.), 2018. New Perspectives in Cultural Resource Management. New York (NY): Routledge.

McManamon, F., Doershuk, J., Lipe, W., McCulloch, T., Polglase, C., Schlanger, S., Sebastian, L. \& Sullivan, L., 2016. Values-based management of archaeological resources at a landscape scale. Advances in Archaeological Practice 4, 132-148.

Mann, C., Plieninger, T., Raymond, C., Tabbush P. \& Tack, J., 2016. Report on Policy Briefs and Set of Recommendations for Landscape Policy and Practice, HERCULES Project Work Package 9. Accessed 9 Dec 2019, http://www.herculeslandscapes.eu/tartalom/HERCULES_WP9_ D9_4_ELO.pdf.

Mayro, L., \& Doelle, W., 2018. Heritage conservation: cultural resource management results for public planning, preservation, research, and outreach, in: F. McManamon (ed.), New Perspectives in Cultural Resource Management New York (NY): Routledge.

Mehrer, M., \& Wescott, K. (eds), 2006. GIS and Archaeological Site Location Modeling. Taylor \& Francis, Boca Raton, Florida.

Mitchell, N., Rössler, M., Tricaud, P-M. (eds), 2009. World Heritage Cultural Landscapes: A Handbook for Conservation and Management. Paris, France: World Heritage Centre, UNESCO. National Academies of Sciences, 2016. A Review of the Landscape Conservation Cooperatives. Washington, DC: The National Academies Press.

Pickett, S. \& Rogers, K., 1997. Patch dynamics: the transformation of landscape structure and function, in: J. Bissonette (ed.), Wildlife and Landscape Ecology: Effects of Pattern and Scale. New York (NY): Springer-Verlag, 101-127.

ReDman, C., 1999. Human Impact on Ancient Environments. Tucson (AZ): University of Arizona Press. Rockman, M., Morgan, M., Ziaja, S., Hambrecht, G. \& Meadow, A., 2016 Cultural Resources Climate Change Strategy. Washington (DC): National Park Service.

SAuer, C., 1967a. The morphology of landscape (1925), in: J. Leighly (ed.), Land and Life: A Selection of Writings of Carl Ortwin Sauer. Berkeley (CA): University of California Press, 
$315-350$.

Sauer, C., 1967b. Foreword to historical geography (1941), in: J. Leighly (ed.), Land and Life: A Selection of Writings of Carl Ortwin Sauer. Berkeley (CA): University of California Press, 351-379.

Schein, R., 1997. The place of landscape: a conceptual framework for interpreting an American scene. Annals of the Association of American Geographers 87(4), 660-680.

Sebastian, L., 2009. Deciding what matters: archaeology, eligibility, and significance, in: L. Sebastian \& W. Lipe (eds), Archaeology and Cultural Resource Management, Visions for the Future. Santa Fe (NM): School for Advanced Research Press, 91-114.

Sebastian, L., Altschul, J., Rohe, C., Thompson, S. \& Hayden, W., 2005. Adaptive Management and Planning Models for Cultural Resources in Oil and Gas Fields: New Mexico Pump III Project. Preservation Research Series 5. Rio Rancho (NM): SRI Foundation. Sebastian, L., \& Lipe, W. (eds), 2010. Archaeology \& Cultural Resource Management: Visions for the Future. Santa Fe (NM): School for Advanced Research Press.

Simpson, I., GuĐmundsson, G., Thomson, A. \& Cluett, J., 2004. Assessing the role of winter grazing in historic land degradation, Mývatnssveit, northeast Iceland. Geoarchaeology 19(5), 471-502.

Stinchcomb, G.E., Messner, T.C., Driese, S.G., Nordt, L.C. \& Stewart, R.M., 2011. Precolonial (A.D. 1100-1600) sedimentation related to prehistoric maize agriculture and climate change in eastern North America. Geology April 2011, 363-366.

TAylor, K. \& Lennon, J., 2011. Cultural landscapes: a bridge between culture and nature? International Journal of Heritage Studies 17(6), 537-554.

Turner, M., Gardner, R. \& O’Neill, R., 2001. Landscape Ecology in Theory and Practice: Pattern and Process. New York (NY): Springer-Verlag.

Turner, S., 2006. Historic landscape characterisation: A landscape archaeology for research, management and planning. Landscape Research 31(4), 385-398.

van Andel, T., Zangger E. \& Demitrack, A., 1990. Land use and soil erosion in prehistoric and historical Greece. Journal of Field Archaeology 17, 379-396.

van DeR Leeuw, S. \& ReDman, C., 2002. Placing archaeology at the center of socio-natural studies. American Antiquity 67, 597-605.

Vanderpot, R., Altschul, J., Lerch, M. \& Heilen, M., 2008. Nonriverine Native-Plant Exploitation in the Sonoran Desert: A View from the Western Papaguería, in: J. Altschul \& A. Rankin (eds), Fragile Patterns: Archaeology of the Western Papaguería. Tucson (AZ): SRI Press, 63-75.

Wandsnider, L., 1998. Regional Scale Processes and Archaeological Landscape Units, in: A. R. Ramenofsky \& A. Steffen (eds), Unit Issues in Archaeology: Measuring Time, Space, and Material. Salt Lake City: University of Utah Press, 87-102.

Wescott, K., \& Brandon R. (eds), 2000. Practical Applications of GIS for Archaeologists: A Predictive Modeling Kit. London: Taylor \& Francis.

Whittlesey, S., 2004. Mesoamerica, the Hohokam, and the Tucson Basin, in: S. WhitTlesey (ed.), Pots, Potters, and Models: Archaeological Investigations at the SRI Locus of the West Branch Site, Tucson, Arizona: Vol. 2. Synthesis and Interpretations. Technical Series No. 80. Tucson (AZ) and Redlands (AZ): Statistical Research, 509-530.

Wu, J., 2010 Landscape of culture and culture of landscape: does landscape ecology need culture? Landscape Ecology 25(8), 1147-1150.

Young, D., 2008. The Archaeology of Shifting Environments in the Great Salt Lake Desert: A Geoarchaeological Sensitivity Model and Relative Chronology for the Cultural Resources of the US Air 
Force Utah Test and Training Range. Davis (CA): Far Western Anthropological Research Group. ZEDEÑO, M., 1997. Landscapes, land use, and the history of territory formation: an example from the Puebloan southwest. Journal of Archaeological Method and Theory 4, 67-103.

ZEDEÑO, M., 2000. On what people make of places: a behavioral cartography, in: M. SCHIFFER (ed.), Social Theory in Archaeology. Salt Lake City (UT): The University of Utah Press, 97-111. Zedeño, M., Austin, D. \& Stoffle, R., 1997. Landmark and landscape: a contextual approach to the management of American Indian resources. Culture \& Agriculture 19(3), 123-129.

Zeanah, D., Carter, J., Dugas, D., Elston, R. \& Hammett, J., 1995. An Optimal Foraging Model of Hunter-Gatherer Land Use in the Carson Desert. Report prepared for U.S. Fish and Wildlife Service and U.S. Department of the Navy, under the U.S. Department of Defense Legacy Program (Legacy 92-0497).

Zeidler, J. (ed.), 2001. Dynamic Modeling of Landscape Evolution and Archaeological Site Distributions: A Three-Dimensional Approach. Fort Collins (CO): Center for Environmental Management of Military Lands. 
